\title{
Assessment of intestinal microbiota of full-term breast-fed infants from two different geographical locations
}

Running title: Microbiota in infants from different locations

Patricia Peso Echarri ${ }^{1,2}$, Carmen Martínez Graciá², Gaspar Ros Berruezo², Inmaculada Vives ${ }^{3}$, Maria Ballesta ${ }^{3}$, Gonzalo Solís ${ }^{4, \mp}$, Isabel Vasallo Morillas ${ }^{5}$, Clara G. de los Reyes-Gavilán ${ }^{1}$, Abelardo Margolles ${ }^{1}$ and Miguel Gueimonde ${ }^{1,{ }^{*}}$

${ }^{1}$ Department of Microbiology and Biochemistry of Dairy Products, Institute of Diary Products of Asturias (IPLA-CSIC), Villaviciosa, Asturias, Spain ${ }^{2}$ Department of Food Science and Nutrition. Veterinary Faculty. University of Murcia. Murcia, Spain.

${ }^{3}$ Paediatrics Service, Virgen de la Arrixaca Hospital, Murcia, Spain. ${ }^{4}$ Paediatrics Service, Hospital Cabueñes, Gijón, SESPA, Asturias, Spain. ${ }^{5}$ Hero España S. A. Murcia, Spain.

${ }^{*}$ Corresponding author: Miguel Gueimonde. Department of Microbiology and Biochemistry of Dairy Products. Instituto de Productos Lácteos de Asturias. CSIC. Ctra. Infiesto s/n, 33300 Villaviciosa, Asturias, Spain. Tel. +34 985892131, Fax.+34 985892233. E-mail; mgueimonde@ipla.csic.es

${ }^{\ddagger}$ Present address: Pediatrics Service, HUCA, Oviedo, SESPA, Asturias, Spain 


\section{Abstract}

2 The intestinal microbiota in the breast-fed infant is considered as ideally

3 healthy. We assessed the microbiota of breast-fed full-term neonates from two

4 different Spanish locations. Statistically significant geographical differences for

5 different bacterial groups were found, underlining the need to consider and

6 define geographical-related effects on microbiota.

7

8

9

10 Keywords: infant microbiota, breastfed infant 
Microbial colonization of the gut provides an essential stimulus for normal

27 intestinal development and maturation of the immune system, contributing to the establishment of a proper intestinal homeostasis and mucosal barrier function [1]. Thus, early establishment of a healthy microbiota provides the first key step in the later well-being of the individual. Gut colonization begins with facultative anaerobes such as enterobacteria and lactobacilli and continues with anaerobic genera such as Bifidobacterium, Bacteroides, and Clostridium. Subsequently, feeding practices affect the population levels of different microbes [2,3]. Breast-milk is the ideal food in early life and it is known to play an important role in the establishment of the intestinal microbiota. The profile of fecal microbiota in the breast-fed infant is considered as ideally healthy. Therefore, promotion of a microbiota resembling that of the healthy breast-fed infant is often taken as a target for improving the functionality of infant formulas by using pro- and prebiotics.

Recent reports have indicated the difficulty of defining the common phylogenetic core of the human healthy intestinal microbiota [4,5]. In infants, the microbiota of the healthy, breast-fed, vaginally delivered, full-term baby is considered the gold standard. However, although the influence of feeding habits, i.e. breast versus formula-fed, and mode of delivery have been extensively studied on the so defined "healthy infant microbiota", the effect of other factors such as geographical origin have been addressed in a limited number of studies [6].

47 The aim of this study was to assess the intestinal microbiota of exclusively breast-fed neonates from two different geographical Spanish locations.

49 Forty healthy full-term exclusively breast-fed infants, born either at the 
51 females) or at the Neonatology Unit of the University Hospital Virgen de la

52 Arrixaca from Murcia (20 infants; 12 males/ 8 females), after an uncomplicated pregnancy were recruited. Infants were vaginally delivered, at a gestational age of 39.2 weeks (95\% Cl: 38.6-39.7) for Asturian infants and 39.1 (95\% Cl: $38.5-$ 39.7) weeks for those from Murcia. Birth weights ranged between 3238 and 3586 grams $(95 \% \mathrm{Cl})$ in Asturias and between 3090 and 3411 grams $(95 \% \mathrm{Cl})$ in infants from Murcia. Microbiota of fecal samples collected at 8, 30 and 90 days of life were compared to ascertain the possible effect of geographical origin of samples. Fecal samples were immediately cooled to $4^{\circ} \mathrm{C}$ after collection, delivered to the laboratory within $4 \mathrm{~h}$, and frozen at $-75^{\circ} \mathrm{C}$ directly on receipt until analysis. None of the mothers or babies received antibiotic therapy during the sampling period. The study was approved by the Regional

63 Committees on Clinical Research from Asturias and Murcia regions. All parents gave written informed consent to participate in the study. Fecal DNA, as well as DNA from bacterial cultures used for calibration curves, was extracted as previously described [7] by using the QIAamp DNA stool mini kit (Qiagen, Hilden, Germany). Quantification of the different bacterial populations in feces was performed by quantitative PCR using primers shown in Table 1. All reactions were performed in a 7500 Fast Real Time PCR System 70 (Applied Biosystems, Foster City, CA) using the SYBR Green PCR Master Mix 71 (Applied Biosystems). $1 \mu \mathrm{L}$ ( $5 \mathrm{ng}$ ) of template fecal DNA and $0.2 \mu \mathrm{M}$ of each primer were used in the $25 \mu \mathrm{L}$ PCR reaction. Thermal cycling consisted of an initial cycle of $95^{\circ} \mathrm{C} 10 \mathrm{~min}$ followed by 40 cycles of $95^{\circ} \mathrm{C} 15 \mathrm{~s}$ and $1 \mathrm{~min}$ at the appropriate temperature (Table 1). In the negative samples the value of the detection limits obtained for the corresponding primer pair was assigned. 
76 Standard curves were made with pure cultures of appropriate strains (Table 1)

77 which were grown overnight in GAM medium (Nissui Pharmaceutical Co, Tokio,

78 Japan) under anaerobic conditions. Samples were analyzed by duplicate in at

79 least two independent PCR runs.

80 No differences in background parameters (birth weight, gestational age) were

81 observed between both study groups. A high inter-individual variability was

82 observed on the levels of the different microbial groups. However, despite this

83 variability our results showed statistically significant $(U$-test; $p<0.05)$ higher

84 levels of Bacteroides ( $8.30 \pm 1.90$ vs. $6.90 \pm 1.86$ Log no. cells $\mathrm{g}^{-1}$ ) and

85 Staphylococcus $(6.64 \pm 1.08$ vs. $5.62 \pm 1.01)$ at 8 days of age and lower of

86 Enterobacteriaceae $(9.17 \pm 0.84$ vs. $9.90 \pm 0.65)$ at 90 days of life in infants from

87 Murcia than in those from Asturias (Figure 1). Similar levels of

88 Enterococcaceae, Clostridia XIVa and IV groups, Atopobium, Bifidobacterium

89 and Lactobacillus were found between both groups (Figure 1). When all the

90 sampling points were taken together, a trend $(p=0.08)$ to lower counts of

91 lactobacilli and higher of $C$. leptum group $(p=0.06)$, as well as significantly

92 higher levels of Bacteriodes and Staphylococcus were observed in Murcian

93 infants as compared to those from Asturias (data not shown). Interestingly, at

94 qualitative level $C$. leptum was more frequently detected in newborns from

95 Asturias than in those from Murcia (64 vs. $25 \%$ of infants at 8 days, 77 vs. $55 \%$

96 at 30 days and 92 vs. $65 \%$ at 3 months of age; Fisher's exact test, $p<0.05$ )

97 whilst no statistically significant differences were obtained in the occurrences of

98 the other microbial groups tested.

99 In both populations a significant negative correlation was observed between the

100 levels of Bacteriodes and those of Enterococcaceae (Pearson's correlation 
101 coefficients, -0.208 and -0.268 for Asturias and Murcia infants, respectively,

$102 \mathrm{p}<0.05$ for both cases) whilst Bacteriodes levels correlate positively with those

103 of Bifidobacterium (Asturias 0.319; Murcia 0.409, $\mathrm{p}<0.05$ for both cases).

104 Similarly significant positive correlations $(p<0.05)$ were observed in both groups

105 of infants between levels of Enterococcaceae and Enterobacteriaceae (0.473

106 and 0.276 for Asturias and Murcia, respectively), between $C$. leptum and $C$.

107 coccoides groups (Asturias 0.234 ; Murcia 0.360) and between bifidobacterial

108 levels and those of lactobacilli (0.368 and 0.258) or Atopobium (0.412 and

1090.213 for Asturias and Murcia, respectively). Interestingly, a very significant

110 positive correlation between Bacteriodes and Atopobium was observed in

111 Asturian infants $(0.662, \mathrm{p}<0.05)$ but not in those from Murcia, whilst the contrary

112 happened between Atopobium and $C$. coccoides $(0.467, p<0.05$ in infants from

113 Murcia).

114 When analysing samples from healthy children and adults, Lay and coworkers

115 [8] did not found any geographical differences on microbiota composition.

116 Contrary to this, when assessing the microbiota of adults and elderly from four

117 European countries, quantitative country-specific differences were reported [9].

118 Moreover, a recent study [6] indicated differences on the gut microbiota

119 composition of 6-weeks-old babies from five European countries. Interestingly,

120 the study by Fallani and co-workers [6] observed, among others, higher levels

121 of Bacteroides in 6-week-old infants from Granada (southern Spain) than in

122 those from other more septentrional European locations. Similarly, in our study

123 exclusively breast-fed, full-term, vaginally delivered infants from Murcia

124 (southern Spain) presented higher levels of Bacteroides than those from 
125 Asturias (northern Spain), indicating that this characteristic may be specific from

126 the south of Spain.

127 In spite of the high inter-individual variability our results evidenced some

128 statistically significant differences between two cohorts of exclusively breast-fed

129 full-term healthy Spanish neonates born in two different locations ( 1000 km far

130 from each other), one in the northern Atlantic coast and the other in the south-

131 east Mediterranean coast. All the infants were born at two hospitals of the

132 Public Health System, where facilities and procedures are expected to be

133 similar and therefore the two groups under study are likely to be quite

134 homogeneous. Therefore, it is not surprising that the observed differences were

135 limited to certain microbial populations whilst most of them showed a high

136 similarity between both infant groups. In agreement with this, the correlations

137 among the levels of the different bacteria analysed seem to be very consistent

138 between both infant groups, although some specific correlations were observed

139 to be different between them. This indicates that not only minor differences in

140 composition are present between both infant groups, but also some interactions

141 among the intestinal microorganisms present may differ depending on the

142 geographical origin.

143 Despite the differences observed in their microbiota, our two individual cohorts

144 represent healthy breast-fed infants. Our study does not allow establishing firm

145 conclusions about the factors explaining these microbiota differences, both

146 locations are similar in terms of number of inhabitants and per capita income,

147 but dietary habits are known to differ between them which is likely to have an

148 influence. Our findings underline the difficulty of defining the healthy intestinal

149 microbiota and suggest that factors related to geographical origin or dietary 
150 background, likely through modulation of breast-milk composition [10], should

151 be also taken into consideration. To this regard, a healthy intestinal microbiota

152 could be defined as the intestinal microbial community that assist the host to

153 maintain a healthy status under certain environmental conditions. This

154 emphasizes that under specific environmental conditions the intestinal

155 microbiota may contribute to health but the same composition under different

156 conditions may lead to disease as suggested by the role that intestinal

157 microbiota seems to play in obesity [11].

158 Although small, geographical or dietary differences in gut microbiota as those

159 reported here may also have a deep impact on pro/prebiotics research.

160 Interestingly, pioneer studies carried out in Finland demonstrated that atopic

161 diseases can be prevented by administration of probiotics [12]. However, a

162 study carried out in Germany following the same design and using the same

163 probiotic strain found no effect [13]. Unfortunately background microbiotas were

164 not compared. If, similarly to our infants, differences in background microbiota

165 exist, they are likely to modify the effect of probiotics on microbiota composition,

166 which may affect the clinical outcome of probiotic/prebiotic intervention studies.

167 It has been previously indicated that a careful characterization of the intestinal

168 microbiota in the target population should constitute the basis for probiotic and

169 prebiotic use [14]. Our results stress this observation and underline the need to

170 define the microbial core of the healthy infant microbiota taking into account the

171 possible differences due to geographical origin.

172

173 Acknowledgements 
174 This work was funded by a CSIC intramural project (Ref. 2008701049) and the

175 Spanish Plan Nacional de I+D+i throught projects Consolider Ingenio 2010

176 Programme (ref. FUN-C-FOOD CSD2007-0623) and AGL-2007-63504. P.

177 Peso-Echarri was the recipient of a Fundación Seneca fellowship

178 (07877/BPS/07).

179

180 Conflict of interest statement

181 All authors disclose any conflict of interest.

182

183 References

1841 Hooper LV, Macpherson AJ. Immune adaptations that maintain homeostasis

185 with the intestinal microbiota. Nat Rev Immunol 2010;10:159-169.

1862 Penders J, Thijs C, Vink C, Stelma FF, Snijders B, Kummeling I, et al.

187 Factors influencing the composition of the intestinal microbiota in early

188 infancy. Pediatrics 2006;118:511-521.

1893 De Filippo C, Cavalieri D, Di Paola M, Ramazzotti M, Poullet JB, Massard S,

190 et al. Impact of diet in shaping gut microbiota revealed by a comparative

191 study in children from Europe and rural Africa. Proc Natl Acad Sci USA

$192 \quad 2010 ; 107: 14691-14696$.

1934 Tap J, Mondot S, Levenez F, Pelletier E, Caron C, Furet JP, et al. Towards

194 the human intestinal microbiota phylogenetic core. Environ Microbiol

$195 \quad 2009 ; 11: 2574-2584$.

1965 Qin J, Li R, Raes J, Arumugam M, Burgdorf KS, Manichanh C, Nielsen T, et

197 al. A human gut microbial gene catalogue established by metagenomic

198 sequencing. Nature 2010;464:59-67. 
1996 Fallani M, Young D, Scott J, Norin E, Amarri S, Adam R, et al. Intestinal

200 microbiota of 6-week-old infants across Europe: Geographic influence

201 beyond delivery mode, breast-feeding and antibiotics. J Pediatric

202 Gastroenterol Nutr 2010;51:77-84.

2037 Gueimonde M, Tölkko S, Korpimäki T, Salminen S. New real-time

204 quantitative PCR procedure for quantification of bifidobacteria in human fecal 205 samples. Appl Environ Microbiol 2004;70:4165-4169.

2068 Lay C, Rigottier-Gois L, Holmstrom K, Rajilic M, Vaughan EE, de Vos WM, et

207 al. Colonic microbiota signatures across five northern european countries.

208 Appl Environ Microbiol 2005;71:4153-4155.

2099 Mueller S, Saunier K, Hanisch C, Norin E, Alm L, Midtvedt T, et al..

210 Differences in fecal microbiota in different European study populations in

211 relation to age, gender and country: a cross-sectional study. Appl Environ

$212 \quad$ Microbiol 2006;72:1027-1073.

21310 Nasser R, Stephen AM, Goh YK, Clandinin MT. The effect of a controlled

214 manipulation of maternal dietary fat intake on medium and long chain fatty

215 acids in human breast milk in Saskatoon, Canada. Int Breasfeed J 2010;5:3.

21611 Ley RE: Obesity and the human microbiome. Curr Opin Gastroenterol

$217 \quad 2010 ; 26: 5-11$.

21812 Kalliomaki M, Salminen S, Arvilommi H, Kero P, Koskinen P, Isolauri E.

219 Probiotics in primary prevention of atopic disease: a randomised placebo-

$220 \quad$ controlled trial. Lancet 2001;357:1076-1079.

22113 Kopp MV, Hennemuth I, Heinzmann A, Urbanek R. Randomized, double-

222 blind, placebo controlled trial of probiotics for primary prevention: no clinical 
effects of Lactobacillus GG supplementation. Pediatrics 2008;121:e850e856.

14 Isolauri E, Salminen S. Probiotics: use in allergic disorders. A Nutrition, Allergy, Mucosal immunology and Intestinal microbiota (NAMI) research group report. J Clin Gastroenterol 2008;42:S91-S96.

15 Matsuki T, Watanabe K, Fujimoto J, Takada T, Tanaka R. Use of 16S rRNA gene-targeted group-specific primers for real-time PCR analysis of predominant bacteria in human feces. Appl Environ Microbiol 2004;70:72207228.

16 Layton A, McKay L, Williams D, Garrett V, Gentry R, Sayler G. Development of Bacteroides 16S rRNA gene TaqMan-based real-time PCR assays for estimation of total, human, and bovine fecal pollution in water. Appl Environ Microbiol 2006;72:4214-4224.

17 Ramirez-Farias C, Slezak K, Fuller Z, Duncan A, Holtrop G, Louis P. Effect of inulin on the human gut microbiota: stimulation of Bifidobacterium adolescentis and Faecalibacterium prausnitzii. Brit J Nutr 2009;101:541-550.

18 Rinttila T, Kassinen A, Malinen E, Krogius L, Palva A. Development of an extensive set of $16 \mathrm{~S}$ rDNA-targeted primers for quantification of pathogenic and indigenous bacteria in faecal samples by real-time PCR. J Appl Microbiol 2004;97:1166-1177.

19 Matsuda K, Tsuji H, Asahara T, Kado Y, Nomoto K. Sensitive quantitative detection of commensal bacteria by rRNA-targeted reverse transcriptionPCR. Appl Environ Microbiol 2007;73:32-39. Erratum in: Appl Environ Microbiol 2007;73:6695. 
Table 1. Bacterial groups, standard cultures, primers and annealing temperatures used in this study

\begin{tabular}{|c|c|c|c|c|}
\hline Microbial target & Strain used for standard curve & Primer Sequence 5'-3' & Tm & Ref \\
\hline $\begin{array}{l}\text { Atopobium group } \\
\text { Atopobium- Collinsella }\end{array}$ & Collinsella intestinalis DSMZ13280 & $\begin{array}{l}\text { F: GGGTTGAGAGACCGACC } \\
\text { R: CGGRGCTTCTTCTGCAGG }\end{array}$ & $55^{\circ} \mathrm{C}$ & $\begin{array}{l}{[15]} \\
{[15]}\end{array}$ \\
\hline $\begin{array}{l}\text { Bacteroides group } \\
\text { Bacteriodes-Prevotella- } \\
\text { Porphiromonas }\end{array}$ & $\begin{array}{l}\text { Bacteriodes thetaiotaomicron } \\
\text { DSMZ2079 }\end{array}$ & $\begin{array}{l}\text { F: GAGAGGAAGGTCCCCCAC } \\
\text { R: CGCKACTTGGCTGGTTCAG }\end{array}$ & $60^{\circ} \mathrm{C}$ & $\begin{array}{l}16] \\
{[17]}\end{array}$ \\
\hline Bifidobacterium & $\begin{array}{l}\text { Bifidobacterium longum } \\
\text { NCIMB8809 }\end{array}$ & $\begin{array}{l}\text { F: GATTCTGGCTCAGGATGAACGC } \\
\text { R: CTGATAGGACGCGACCCCAT }\end{array}$ & $60^{\mathrm{a}} \mathrm{C}$ & $\begin{array}{l}{[5]} \\
{[5]}\end{array}$ \\
\hline $\begin{array}{l}\text { Clostridia XIVa group } \\
\text { C.coccoides-E. rectale }\end{array}$ & Clostridium coccoides DSMZ935 & $\begin{array}{l}\text { F: CGGTACCTGACTAAGAAGC } \\
\text { R: AGTTTYATTCTTGCGAACG }\end{array}$ & $55^{\circ} \mathrm{C}$ & $\begin{array}{l}18] \\
{[18]}\end{array}$ \\
\hline $\begin{array}{l}\text { Clostridia IV } \\
\text { C. leptum-F. praustnitzii }\end{array}$ & Clostridium leptum DSMZ753 & $\begin{array}{l}\text { F: TTAACACAATAAGTWATCCACCTGG } \\
\text { R: ACCTTCCTCCGTTTTGTCAAC }\end{array}$ & $60^{\circ} \mathrm{C}$ & $\begin{array}{l}{[17]} \\
{[17]}\end{array}$ \\
\hline Enterobacteriaceae & Escherichia coli LMG2092 & $\begin{array}{l}\text { F: TGCCGTAACTTCGGGAGAAGGCA } \\
\text { R: TCAAGGACCAGTGTTCAGTGTC }\end{array}$ & $60^{\circ} \mathrm{C}$ & $\begin{array}{l}19] \\
{[19]}\end{array}$ \\
\hline Enterococcaceae & Enterococcus faecalis IPLAIF3/1 & $\begin{array}{l}\text { F: CCCATCAGAAGGGGATAACACTT } \\
\text { R: ACCGCGGGTCCATCCATC }\end{array}$ & $60^{\circ} \mathrm{C}$ & $\begin{array}{l}19] \\
{[19]}\end{array}$ \\
\hline Lactobacillus Group & Lactobacillus gasseri IPLAIF7/5 & $\begin{array}{l}\text { F: AGCAGTAGGGAATCTTCCA } \\
\text { R: CATGGAGTTCCACTGTCCTC }\end{array}$ & $60^{\circ} \mathrm{C}$ & $\begin{array}{l}\text { [18] } \\
\text { This study }\end{array}$ \\
\hline Staphylococcus & $\begin{array}{l}\text { Staphylococcus epidermidis } \\
\text { IPLAIF1/6 }\end{array}$ & $\begin{array}{l}\text { F: ACGGTCTTGCTGTCACTTATA } \\
\text { R: TACACATATGTTCTTCCCTAATAA }\end{array}$ & $60^{\circ} \mathrm{C}$ & $\begin{array}{l}{[19]} \\
{[19]}\end{array}$ \\
\hline
\end{tabular}


Figure 1. Bacterial levels, at the different sampling times, determined by qPCR in feces of breast-fed infants from two Spanish locations (about $1000 \mathrm{~km}$ apart from each other); Asturias (black diamonds) or Murcia (open squares).

Asterisks indicate statistically significant differences between both groups at the corresponding sampling time $(p<0.05)$. 
Figure 1
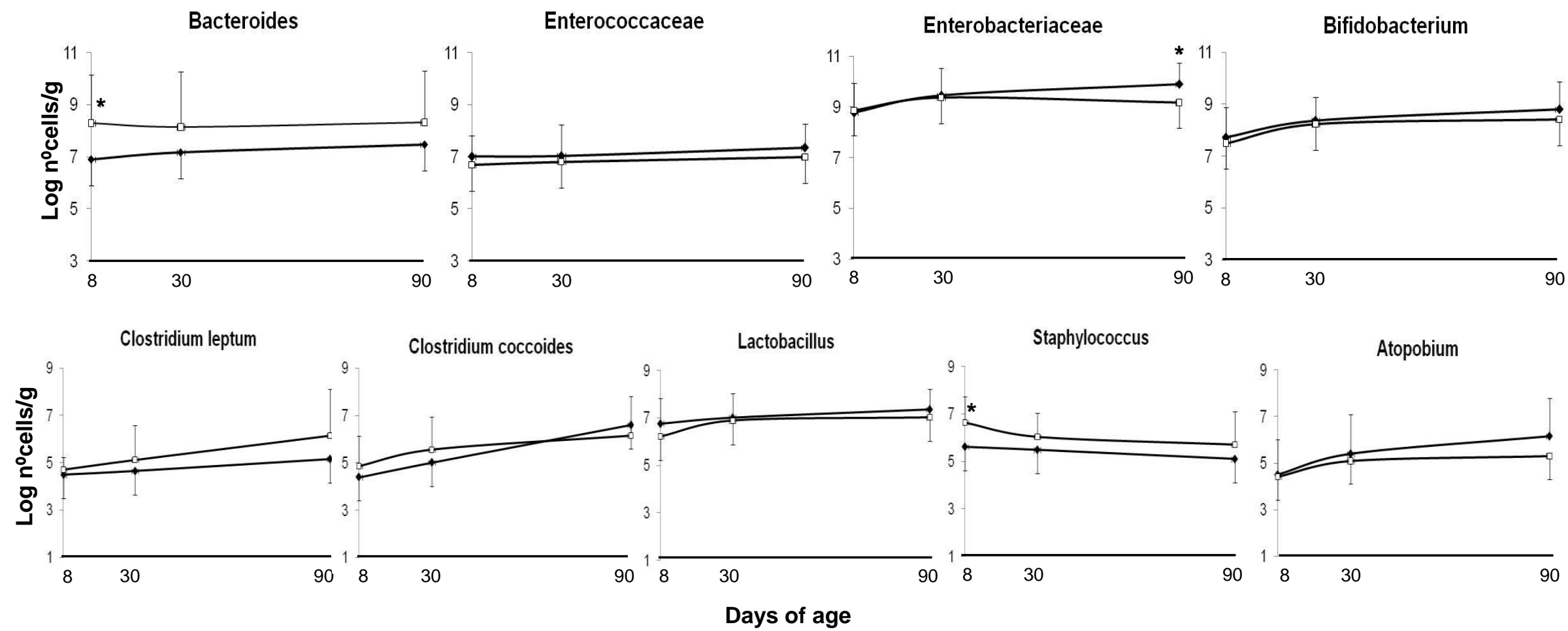

Days of age 